\title{
Comparison of Percutaneous Ablation Technologies in the Treatment of Malignant Liver Tumors
}

\author{
Hyeon Yu, MD ${ }^{1}$ Charles T. Burke, MD, FSIR ${ }^{1}$ \\ ${ }^{1}$ Division of Vascular and Interventional Radiology, Department of \\ Radiology, University of North Carolina School of Medicine, \\ Chapel Hill, North Carolina
}

Semin Intervent Radiol 2014;31:129-137

\author{
Address for correspondence Hyeon Yu, MD, Division of Vascular and \\ Interventional Radiology, Department of Radiology, University of \\ North Carolina School of Medicine, 2016A Old Clinic, Campus Box \\ 7510, Chapel Hill, NC 27599-7510 (e-mail: hyeon_yu@med.unc.edu).
}

\author{
Abstract \\ Keywords \\ - percutaneous \\ chemical ablation \\ - radiofrequency \\ ablation \\ - irreversible \\ electroporation \\ - cryoablation \\ - microwave ablation \\ - high-intensity- \\ focused ultrasound \\ ablation \\ - interventional \\ radiology
}

Tumor ablation is a minimally invasive technique used to deliver chemical, thermal, electrical, or ultrasonic damage to a specific focal tumor in an attempt to achieve substantial tumor destruction or complete eradication. As the technology continues to advance, several image-guided tumor ablations have emerged to effectively manage primary and secondary malignancies in the liver. Percutaneous chemical ablation is one of the oldest and most established techniques for treating small hepatocellular carcinomas. However, this technique has been largely replaced by newer modalities including radiofrequency ablation, microwave ablation, laser-induced interstitial thermotherapy, cryoablation, high-intensity-focused ultrasound ablation, and irreversible electroporation. Because there exist significant differences in underlying technological bases, understanding each mechanism of action is essential for achieving desirable outcomes. In this article, the authors review the current state of each ablation method including technological and clinical considerations.
Objectives: Upon completion of this article, the reader will be able to describe the underlying mechanism of various ablation techniques, including percutaneous chemical ablation, irreversible electroporation, high-intensity-focused ultrasound ablation, laser ablation, microwave ablation, radiofrequency ablation, and cryoablation, as well as the clinical outcomes in the management of patients with primary and secondary liver tumors.

Accreditation: This activity has been planned and implemented in accordance with the Essential Areas and Policies of the Accreditation Council for Continuing Medical Education (ACCME) through the joint providership of Tufts University School of Medicine (TUSM) and Thieme Medical Publishers, New York. TUSM is accredited by the ACCME to provide continuing medical education for physicians.

Issue Theme Tumor Ablation; Guest Editor, Charles T. Burke, MD, FSIR
Credit: Tufts University School of Medicine designates this journal-based CME activity for a maximum of 1 AMA PRA Category 1 Credit $^{\mathrm{TM}}$. Physicians should claim only the credit commensurate with the extent of their participation in the activity.

\section{Percutaneous Chemical Ablation}

Percutaneous chemical ablation is a relatively safe and effective procedure used in the treatment of small hepatocellular carcinoma (HCC). It is well tolerated by patients and has very low reported major and minor complication rates $(\sim 2 \%))^{1,2}$ Although the technique requires adequate expertise in placing the needle with imaging guidance, the procedure is simple and does not require any specialized equipment,
Copyright @ 2014 by Thieme Medical Publishers, Inc., 333 Seventh Avenue, New York, NY 10001, USA. Tel: +1(212) 584-4662.
DOI http://dx.doi.org/ 10.1055/s-0034-1373788. ISSN 0739-9529. 
except multi-side-hole needle if one chooses. Chemical agents for percutaneous ablation include ethanol, acetic acid, and sodium hydroxide. ${ }^{2}$ Percutaneous ethanol injection (PEI) is well established and the most commonly used chemical ablation technique. It was shown that PEI can safely achieve complete necrosis of small HCCs, and achieve 5year survival rates of 32 to $38 \%$ in nonrandomized trials in the 1990 s. $^{3-5}$ However, due to multiple session numbers, high local tumor progression rate, and variable ablation zone in PEI compared with radiofrequency (RF) ablation, the use of PEI is now limited to situations when RF ablation should not be performed, such as when the tumor is in close proximity to large vessels or critical organs. ${ }^{1,6-8}$ In one study evaluating the treatment of small HCC, RF ablation demonstrated an approximately $20 \%$ higher survival rate at 3 to 4 years and fewer treatment sessions than PEI in three randomized controlled trials. ${ }^{9-11}$ It has been confirmed again in recent meta-analyses evaluating these randomized controlled trials that RF ablation is better than PEI in the treatment of small HCC. ${ }^{12,13}$

The basic mechanism of action of ethanol is through cytoplasmic dehydration, denaturation of cellular proteins, and microvascular thrombosis. These changes eventually result in coagulation necrosis of tumor tissue. ${ }^{2,14}$ For a chemical agent to exert its cytotoxic effect, it must be transported from the point of injection through the interstitial space into the cytoplasmic compartment of the tumor. This is primarily accomplished through two mechanisms: diffusion and convection. Chemical agents with a relatively low molecular weight, such as ethanol and acetic acid, are transported mainly by diffusion and rely on the concentration gradient between two compartments. ${ }^{15}$ Direct injection of a high-concentration agent using a multi-side-hole needle placed into a tumor at multiple sites will not only increase the interstitial pressure but also establish a much higher local concentration gradient, resulting in high convective and diffusive flux of the agent into the cytoplasm. Factors associated with homogeneous diffusion of ethanol include soft and small $(<3 \mathrm{~cm})$ hepatic tumors with fewer septations or daughter nodules. ${ }^{2}$ While ethanol is incapable of penetrating the septae, acetic acid has an advantage of dissolving lipids and infiltrating the septae and tumor capsules. ${ }^{16}$ As a result, the total injected volume and the number of treatment sessions with acetic acid are less than those with ethanol to achieve the same cytotoxic effect. The typical volume of acetic acid needed for each treatment session is approximately one-third the volume used for ethanol ablation based on earlier observations of animal study and clinical experiences. $^{17,18}$

One other chemical agent that has been used is sodium hydroxide. Sodium hydroxide has been studied in an animal model that demonstrated that sodium hydroxide has a concentration-dependent necrotizing effect with less systemic toxicity. ${ }^{19}$ When acetic acid and sodium hydroxide are mixed together, an exothermic neutralization reaction occurs. Exothermic neutralization is a chemical reaction between an acid and a base in which heat, salt, and water are produced. In a recent study, Farnam et al injected acetic acid and sodium hydroxide simultaneously into an ex vivo porcine liver to investigate the exothermic neutralization reaction for potential use in tissue ablation. ${ }^{20}$ The authors confirmed that the reaction between the two reagents released a significant amount of heat energy at the site of injection and created histologic changes consistent with coagulation necrosis. A high concentration and volume of acetic acid and sodium hydroxide correlated with higher temperatures and larger areas of gross pathologic changes.

\section{Irreversible Electroporation}

Percutaneous irreversible electroporation (IRE) is a nonthermal ablative technique in which short (microsecond to millisecond) pulses of high voltage electrical energy are applied to a targeted tissue through electrodes. ${ }^{21}$ Ninety pulses of 1,000 to $3,000 \mathrm{~V} / \mathrm{cm}$ direct current energy are delivered to generate destabilizing electrical potential across the cell membrane, resulting in the formation of permanent nanopores in the lipid bilayer. This irreversible disruption and increased permeability of the cell membrane is the key mechanism for cell death. $^{22-24}$

Electroporation is a dynamic phenomenon that can cause either reversible or irreversible damage, depending on the transmembrane electric voltage to the cell membrane. If the cells are located within areas where the electric field magnitude is greater than the threshold, reversible electroporation occurs in the cell membranes. If the voltage surpasses a second threshold, it creates irreversible and persistent pores in the cell membrane that induce cell death. ${ }^{25}$

IRE has been investigated by Edd et al in an animal model to analyze the efficacy as an independent tissue ablation method. ${ }^{24}$ In perfusion-fixed animal livers, the authors observed microvascular occlusion, endothelial cell necrosis, and diapedeses, resulting in ischemic damage to the parenchyma and massive accumulation of erythrocytes in sinusoids approximately 3 hours after electroporation. However, the integrity of vascular structures around the treated site was preserved in this study.

The finding of preserved blood vessels at the margin of ablated tissue was again observed in a study with porcine liver by Rubinsky et $\mathrm{al}^{21}$ in 2007 . These authors hypothesized that the vessel-preserving effect of IRE is likely caused by a higher proportion of collagenous connective tissue and elastic fiber, as well as the lack of a normal cellular membrane in the vessel wall. This is supported by the finding of mild inflammatory change in the vessels located in the ablated zone.

In a recent study using Yorkshire pig livers, Lee et al demonstrated that IRE is a safe and effective ablative method, inducing complete tissue death via apoptosis while fully preserving the periablative zone structures including blood vessels, bile ducts, and surrounding normal tissues. ${ }^{26}$ This finding is explained by the presence of gap junctions of the smooth muscle cells, in addition to higher contents of collagenous and elastic fibrous tissue in both bile ducts and blood vessels. Gap junctions are the distinctive cellular structure of the smooth muscle cells that may 
act as a barrier preventing the electrical current from traveling through the junction between cells, thereby the integrity of the smooth muscle cell membrane is not disrupted or changed. Hence, the bile ducts and vessels around the ablated zone are preserved.

This advantage of IRE with lack of a heat-sink effect enables better tumor ablation with less risk of damage to the adjacent vessels, ducts, or critical organs compared with other thermal ablation techniques including RF ablation, microwave (MW) ablation, and cryoablation. For this reason, interest in IRE application is increasing, especially for use in the pancreas or liver where vital structures and ducts can easily be damaged by thermal ablation methods.

The safety of IRE for tumor ablation in humans was first reported by Thomson et $\mathrm{al}^{27}$ in a single-center nonrandomized cohort study in 2011. In the 38 patients with advanced malignant tumors in the liver, kidney, or lung, a total of 69 IRE ablations were performed with no mortalities at 30 days. Complete ablation was achieved in 66\% of tumors; most treatment failures occurred in renal and lung tumors. Adverse events directly related to electroporation included cardiac dysrhythmias and obstruction of the upper ureter. Though there was one unintentional ablation of the adrenal gland, there was no other evidence of adjacent organ damage related to the IRE. Owing to transient ventricular arrhythmia occurring in four patients, ECG-synchronized delivery was used subsequently in the remaining patients. The authors concluded that IRE is safe for human clinical application when adequate ECG synchronization is used.

Narayanan et al reported on the feasibility and clinical safety of computed tomography-guided percutaneous IRE in 14 patients with unresectable locally advanced pancreatic cancer. ${ }^{28}$ The percutaneous pancreatic IRE procedure was well tolerated with a low complication rate. Complications included spontaneous pneumothorax and pancreatitis that were self-limited and completely reversible; there were no deaths related to the procedure.

The safety and efficacy of percutaneous IRE ablation for hepatic tumors located centrally or close to the major bile ducts, portal pedicles, or hepatic veins has been evaluated in several studies. ${ }^{29-31}$ Kingham et al tested the safety of IRE for treating hepatic tumors located within $1 \mathrm{~cm}$ from major hepatic veins or major portal pedicles. ${ }^{29}$ In this study, they reported complications including cardiac arrhythmia and portal vein thrombosis. However, the overall morbidity was only $3 \%$ with no treatment-associated mortalities. Cannon et al also examined the safety and early efficacy of IRE for hepatic malignancies in proximity to vital structures. ${ }^{31} \mathrm{~A}$ total of 48 procedures were performed in 44 patients with centrally located tumors in proximity to major vascular/ biliary structures or adjacent organs. Technical success was achieved in $100 \%$, and five patients had nine transient adverse events with complete resolution within 30 days. In a retrospective study, Silk et al suggested that IRE may be an option for centrally located peribiliary hepatic tumors. ${ }^{30}$ Although these studies demonstrated the safety of IRE, larger studies and longer follow-up are necessary to determine long-term efficacy.

\section{High-Intensity-Focused Ultrasound Ablation}

High-intensity-focused ultrasound ablation (HIFU) is one of the thermal ablation therapies using high temperature to treat a targeted lesion. It is a noninvasive therapeutic modality, in which focused acoustic energy is precisely delivered from an extracorporeal source to the focal zone. This highintensity-focused energy is then converted to heat, which destroys diseased tissues without damaging overlying and surrounding normal structures.

A high-frequency ultrasound beam $(0.5-10 \mathrm{MHz})$ is generated by a therapeutic ultrasound transducer and arranged into a spherical form by an acoustic lens to create a small and discrete focal point. As the beam approaches the focal point, the power density of the converging ultrasound increases and the energy is accumulated at the focal zone. This phenomenon subsequently induces coagulation necrosis of the targeted lesion by creating acoustic cavitation and elevating tissue temperature to above $60^{\circ} \mathrm{C}^{32,33}$ Temperatures can rise from 65 to $85^{\circ} \mathrm{C}$; however, higher temperatures are avoided to prevent boiling of liquids inside the tissue.

HIFU technology was first described by Lynn et $\mathrm{al}^{34}$ in 1942. These authors designed an efficient generator of focused ultrasound that was successfully operated to produce focal heating in the center of the liver tissue with minimal effects at the surface and no effects on the intervening tissue. In animals, high-intensity focal ultrasound produced local cerebral changes through intervening scalp, skull, and meninges. Since its first introduction in 1942, the technology of HIFU has continuously evolved, and recent developments have allowed its application to treat tumors of various solid organs, including the pancreas, liver, prostate, breast, uterus, bone, and soft tissue. ${ }^{35-38}$

Recently, the addition of magnetic resonance (MR) guidance for HIFU has generated a renewed interest in this technology for tumor ablation. MR imaging-guided HIFU or focused ultrasound is mainly used in the treatment of uterine fibroids for which it has been approved for use by the U.S. Food and Drug Administration (FDA). It is, however, being tested to determine its clinical application for other benign and malignant tumors of the breast, prostate, liver, and uterus. $^{39,40}$

In the liver, the utility of HIFU has been examined in the treatment of unresectable HCC or metastases. Despite the challenges of targeting within the liver due to respiratory motion, HIFU has been shown to be safe and effective. Xu et al reported their experience in treating 145 patients in whom symptoms were relieved in $84.4 \%$ and tumor size was decreased by various degrees. ${ }^{41}$ The 2 -year overall survival rate was dependent on tumor stages. HIFU has also been shown to be safe in treating liver tumors located in close proximity to major vessels. In a study by Zhang et $\mathrm{al}^{42} 39$ patients with HCC were treated with HIFU and there was no evidence of any major blood vessel injury when treating tumors located less than $1 \mathrm{~cm}$ from the inferior vena cava (IVC), main hepatic vein, or portal vein.

In a single-center study, $\mathrm{Ng}$ et al reported that HIFU, when used as the primary therapy, achieved an overall effectiveness 
rate of $79.5 \%$ in 49 patients with unresectable HCC. ${ }^{32}$ When the total number of ablated tumors is considered, a complete ablation rate reaches $91 \%$ for small $\mathrm{HCC}(\leq 3 \mathrm{~cm})$. The 1 - and $3-$ year overall survival rates were 87.7 and $62.4 \%$, respectively. Child-Pugh liver function grading was the most significant prognostic factor influencing the overall survival rate. The authors concluded that HIFU is an effective modality in the treatment of unresectable HCC, with a high technique effectiveness rate and favorable survival outcomes.

Because the ultimate goal for liver ablation is to improve the overall survival of the patient, it is critical when assessing new technologies that survival data be examined. In a recent study, Cheung et al compared survival rates between patients with small HCC $(\leq 3 \mathrm{~cm})$ treated with HIFU and RFA. ${ }^{43}$ In this study, the 1- and 3-year overall survival rates of HIFU and RF ablation groups were 97.4 versus $94.6 \%$ and 81.2 versus $79.8 \%$, respectively ( $p=0.530$ ). The corresponding 1 - and 3-year disease-free survival rates were 63.6 versus $62.4 \%$ and 25.9 versus $34.1 \%$, respectively ( $p=0.683$ ). The authors concluded that in the treatment of small HCC, HIFU provides outcomes comparable to that of RF ablation.

Transarterial chemoembolization (TACE) has been combined with thermal ablation therapies in an attempt to achieve more complete necrosis of HCC. Because TACE may reduce blood flow of a tumor, heat loss caused by adjacent vessels may be reduced. ${ }^{44}$ Likewise, HIFU has been used in conjunction with TACE and a randomized clinical trial has shown a significant survival benefit in the group with TACE and HIFU compared with the TACE-only group. ${ }^{45}$ Jin et al reported a similar experience of HIFU and TACE in patients with unresectable HCC. ${ }^{46}$ This study demonstrated that $45.2 \%$ of patients achieved complete tumor ablation when TACE was combined with HIFU. Ablation response and tumor size were major prognostic factors.

Other indications for HIFU have been investigated in animal studies by Vaezy et al and Noble et al. ${ }^{47,48}$ Namely, HIFU has been tested in the treatment of a variety of benign splenic conditions. Specifically, HIFU has been found to be effective in achieving hemostasis in hemorrhagic spleen models with no apparent harmful effects to the spleen. Another recent experimental study demonstrated HIFU to be feasible and effective for treating splenomegaly and hypersplenism. ${ }^{49}$ Zhu et al also reported the efficacy and safety of HIFU in patients with HCC and hypersplenism. ${ }^{38}$ After HIFU treatment, mean splenic ablation of approximately $28 \%$ was achieved and the white blood cell count, platelet count, and liver function were improved.

\section{Laser Ablation}

Percutaneous laser ablation is a hyperthermia-based technique that destroys targeted tissues by using heat energy converted from absorbed light. Laser light is transmitted to the lesion via bare-tip quartz fibers with diameter of 300 to $600 \mu \mathrm{m}$ inserted through multiple small-caliber needles (21 gauges). Inside the tissue, laser light travels for a short distance $(12-15 \mathrm{~mm})$ as a result of scattering, reflection, and absorption. ${ }^{50}$ The absorbed light energy is then evenly distributed (mainly by scattering) and is converted to heat that is further spread by conduction, creating a large area of coagulation necrosis. ${ }^{51-53}$ Using 21-gauge needles for placing multiple fibers is considered less traumatic compared with 7F or 9F single cannulation needles in patients with liver cirrhosis who have higher risk of bleeding. ${ }^{54}$

Because of its optimal penetration depth into surrounding tissues, since the first introduction of phototherapy in tumors in 1983, Nd:YAG (neodymium:yttrium aluminum garnet) lasers (wavelength, $1,064 \mathrm{~nm}$ ) have been widely used in the treatment of various liver malignancies. ${ }^{55,56}$ The optimal penetration of laser light is directly associated with a lower temperature gradient throughout the ablation zone, less risk of carbonization and vaporization of tissue, and better treatment results for tumors. ${ }^{57}$ The penetration depth of laser light is greater in metastatic tumors than in normal liver tissue, and coagulation necrosis results in reduced penetration by approximately $20 \%$ in both tissues. ${ }^{57,58}$ A single baretip fiber can create a spherical ablation zone with a diameter of 12 to $16 \mathrm{~mm} .{ }^{59}$ When multiple fibers are arranged in the tumor, the area of ablation can be significantly increased.

In a single-center study, Pacella et al first reported that laser ablation is a highly effective therapeutic modality in patients with HCC smaller than $4 \mathrm{~cm} .{ }^{60}$ The study, involving 82 patients with 99 lesions, demonstrated a complete tumor ablation rate of $90.9 \%$. The safety of the procedure was investigated by Arienti et al in a larger multicenter study involving nine centers in Italy with 520 patients who underwent 1,004 treatment sessions for 647 HCC nodules. ${ }^{61}$ There were four $(0.8 \%)$ deaths and 15 (1.5\%) major complications without any tumor seeding. Major complications were associated with excess energy deposition and high-risk locations. Sixty-two (6.2\%) sessions resulted in minor complications associated with excess energy, high bilirubin level, and low prothrombin time. Complete necrosis was achieved in $60 \%$ of all HCCs, and in $81.1 \%$ of small nodules $(\leq 3 \mathrm{~cm})$. The authors concluded that the procedure is safe in the treatment of small HCCs. In a separate retrospective study evaluating 87 patients with 180 liver metastases from colorectal carcinoma, Puls et al reported a technical success rate of $99 \%$, an effectiveness rate of $85.6 \%$ on follow-up after 24 to 48 hours, and a local tumor progression rate of $10 \%$ after 6 months. ${ }^{62}$ Median survival time was 54 months and survival rates were $95.7 \%$ at 1 year, $86.2 \%$ at 2 years, $72.4 \%$ at 3 years, $50.1 \%$ at 4 years, and $33.4 \%$ at 5 years.

As laser ablation is increasingly being used in the treatment of liver malignancies including HCC and metastases, the technology is being compared with RF ablation in an attempt to validate its technical reliability and efficacy. ${ }^{59}$ Recently, Orlacchio et al compared the two ablation technologies in the treatment of HCC smaller than $4 \mathrm{~cm}$ in patients with liver cirrhosis. ${ }^{63}$ Thirty patients with single HCC $\leq 4 \mathrm{~cm}$ in diameter were randomly assigned to one of two treatments and followed up for up to 12 months. Complete response rates with laser and RF ablations were 87 and 93\%, respectively; this finding was not statistically significant. There were also no differences in the overall local recurrence-free survival rates between the two groups; however, patients treated with laser ablation did show a higher recurrence rate for HCC larger 
than $2 \mathrm{~cm}(p=0.0081)$, and tumor necrosis factor- $\alpha$ with postablation syndrome was found to be significantly higher in the RF ablation group ( $p<0.05)$. Overall, in this study, RF ablation appears more effective compared with laser ablation for treating larger HCCs. However, laser ablation can be considered an alternative treatment option for tumors smaller than $2 \mathrm{~cm}$ for its lower complications rates.

Laser ablation may also be combined with other modalities to achieve an increased volume of tumor necrosis. In an animal study, Zou et al investigated the effects of laser ablation combined with PEI on rabbit VX2 liver tumors. ${ }^{64}$ VX2 tumors in the liver of 80 rabbits were randomly separated into four groups; each group was treated with laser ablation alone, PEI alone, laser ablation immediately followed by PEI, or PEI immediately followed by laser ablation. The study demonstrated that combined therapy with PEI immediately followed by laser ablation resulted in a significantly larger volume of coagulation necrosis with reduced residual tumor volume. It was hypothesized that tissue destruction by ethanol may have resulted in increased thermal conduction. In addition, PEI is associated with a sclerosing effect on blood vessels, thus reducing the heat-sink effect and enhancing the effect of the laser ablation.

\section{Microwave Ablation}

In MW ablation, the mechanism of heat generation is based on rapid frictional movement of water molecules in the highfrequency (900-2,500 MHz) electromagnetic field. An oscillating electromagnetic field around the antenna forces water molecules to continuously realign, resulting in high kinetic energy that is converted to heat in the tissue. ${ }^{11,65,66}$

MW ablation has several advantages, including greater penetration of energy into tissue (resulting in a larger area of ablation), less susceptibility to convective heat-sink effect from surrounding vessels, higher intratumoral temperatures, faster ablation times, and simultaneous activation of multiple antennae. ${ }^{66-69}$ In addition, MW ablation does not require grounding pads or other ancillary devices. Even in tissues with high impedance, such as lung or charred and desiccated tissues, MW can be used effectively due to its low sensitivity to local variation in tissue physical properties. The incidence and severity of postablation syndrome (flu-like illness, lowgrade fever, nausea, and/or vomiting) is found to be similar to that reported for RF ablation. Postprocedural pain for MW ablation is correlated with total ablation volume. ${ }^{70}$

The safety, effectiveness, and survival rates have been reported in several studies with MW ablation in the treatment of HCC. In a cohort study with 234 patients who underwent MW ablation, Dong et al showed a complete ablation rate of $89 \%$, local recurrence rate of $7 \%$, and cumulative survival rates at $1,2,3,4$, and 5 years of 92.7, 81.6, 72.9, 66.4 , and $56.7 \%$, respectively. ${ }^{71}$ In a retrospective study of 102 patients with HCC, Lu et al reported that MW ablation and RF ablation are both effective in treating HCC. The local tumor control, complications related to treatment, and long-term survivals were equivalent for the two modalities ${ }^{72}$; complete tumor ablation rates with MW ablation and RF ablation were
94.9 and $93.1 \%$, respectively. The local recurrence rate was $11.8 \%$ for MW ablation versus $20.9 \%$ for RF ablation, and there was no significant difference between the two modalities in treating either large or small tumors. In a well-matched randomized controlled trial involving 72 patients with HCC, Shibata et al compared MW ablation with RF ablation. ${ }^{73}$ This study found that complete therapeutic effects with RF ablation and MW ablation were 96 and 89\%, respectively. Complication rates and rates of residual foci of untreated disease were also equivalent for both ablation techniques.

Recent studies using improved MW technology with more powerful generators have demonstrated improved efficacy by creating larger ablation zones. Using a new MW device with a 2.45-MHz generator, Poggi et al were able to achieve an overall complete ablation rate of $94.3 \%$ in patients with $\mathrm{HCC}^{74}$; for small HCC (diameter $\leq 3 \mathrm{~cm}$ ), complete necrosis was obtained in $100 \%$. The rates of complete ablation for the intermediate $(3-5 \mathrm{~cm})$ and large lesions $(\geq 5 \mathrm{~cm})$ were 90 and $69 \%$, respectively.

The evidence supporting MW ablation in the treatment of metastatic liver tumors is limited. In one of the first studies, Shibata el al compared laparoscopic-guided MW ablation and surgical resection in patients with metastatic colorectal carcinoma in the liver. ${ }^{75}$ There were no significant differences in mean survival times, complications, and mean disease-free intervals between the two groups. Estimated 1-, 2-, and 3year survival rates were 71,57 , and $14 \%$ for MW ablation and 69,56 , and $23 \%$ for surgical resection, respectively. Tanaka et al also reported the efficacy of MW ablation combined with hepatectomy compared with hepatectomy alone for multiple bilobar colorectal metastases to the liver. ${ }^{76}$ Although more metastases were found in the group with MW ablation and resection, there were no significant differences in survival rates or in the pattern of progression between the two groups. The study concluded that MW ablation plus hepatic resection expanded the indications for operation to treat multiple bilobar liver metastases, with survival rates similar to those in less-involved hepatic resection patients.

\section{Radiofrequency Ablation}

In RF ablation, a complete electrical circuit is formed across the patients' body between a needle electrode and largesurface ground pads. Rapidly alternating RF current (300-500 $\mathrm{KHz}$ ) is then generated around an electrode and is propagated through the tissue, resulting in resistive heating (the Joule effect). Although initial direct heating occurs within a short distance of the electrode, a larger ablation zone is eventually created by thermal conduction, inducing cell death by coagulation necrosis. ${ }^{68}$

Since RF ablation was first used for $\mathrm{HCC}^{66}$ in 1990, the technique has been expanding its role in the treatment of primary and secondary hepatic malignancies. In patients with small $(\leq 3 \mathrm{~cm})$ to medium $(3-5 \mathrm{~cm})$ sized HCC, RF ablation has achieved complete ablation rates of over $80 \%$ in a single treatment session and over $90 \%$ in two sessions, with 5year survival rates of 40 to $58 \%$. Local progression rates after complete ablation are 1 to $12 \% .^{8,72-74,77-80}$ Major 
complications include peritoneal hemorrhage, bile duct injury, abscess, and intestinal perforation, with acceptable rates of these complications ranging from 0.9 to $5.0 \%{ }^{75,79}$ In the treatment of large HCC ( $\geq 5 \mathrm{~cm})$, conventional RF ablation is limited mainly by incomplete ablation, with reported complete ablation rate of $62 \%$ for tumors measuring 5 to $7 \mathrm{~cm} .{ }^{81}$ However, the efficacy is clearly improved when new devices are used. In a separate study using three bipolar electrodes and internally cooled electrodes, complete ablation rates were 81 and $90 \%$, respectively, in patients with large HCC. $^{82,83}$

RF ablation has been compared with PEI in the treatment of unresectable HCC $(2.2-2.9 \mathrm{~cm})$ in several randomized controlled trials. ${ }^{84}$ Meta-analysis of these trials showed better 1- and 3-year overall survival in patients treated with RF ablation compared with those treated with PEI. In the RF ablation group, disease-free survival rates were significantly better, and disease recurrence rates at the ablation site were significantly worse than in the PEI group. ${ }^{9-11,85}$

\section{Cryoablation}

Cryoablation is based on the rapid cooling of the cryoprobe by the Joule-Thompson effect. ${ }^{86}$ As high-pressure argon gas is forced through a narrow opening at the distal portion of the probe and then rapidly expanded to atmospheric pressure, the temperature of the metallic probe is decreased. This cold temperature is transferred to surrounding tissue by convection and conduction. When helium gas passes through the same system, it causes warming of the cryoprobe and thawing of the tissue. ${ }^{87}$ Cell death is caused by direct intracellular ice crystal formation, resulting in physical damage to the plasma and cytoplasmic organelle membranes. ${ }^{88}$ During thawing, intracellular ice crystals continuously grow, maximizing their biocidal effects. ${ }^{89}$ If ice crystal formation occurs in the vascular endothelial cells of blood vessels supplying the targeted lesion, indirect cellular injury is induced by ischemia and inflammation. ${ }^{89-91}$

Cryoablation has been used to treat both primary and metastatic liver tumors. A multicenter retrospective study of cryoablation for liver tumors including metastases and HCC for over 7 years reported that cryoablation for noncolorectal metastases had significant long-term survival benefit and is a useful tool for controlling symptoms. ${ }^{92}$ Recently, Xu et al evaluated the efficacy of sequential use of TACE and percutaneous cryoablation compared with cryoablation alone for unresectable HCC. A total of 130 patients with intermediate to large HCC (mean size $4.6 \mathrm{~cm}$ ) were treated with cryoablation alone. ${ }^{93}$ During a mean follow-up period of $42 \pm 17$ months, local recurrence was observed in $23 \%$ of patients in cryoablation-alone group, compared with $11 \%$ in cryoablation plus TACE group ( $n=290$ ). The overall 1-, 2-, 3-, 4-, and 5 -year survival rates in cryoablation-alone group were 72,57 , 47,39 , and $31 \%$, respectively. Although, the 1 - and 2 -year survival rates were similar between the two groups, the 4and 5-year survival rates were 49 and $39 \%$ in sequential TACE-cryoablation group, higher than those (29 and 23\%) in cryoablation-alone group $(p=0.001)$. The authors con- cluded that when TACE is combined with cryoablation, the efficacy is increased and adverse effects decreased for patients with unresectable HCC.

In a retrospective study by Adam et al in 2002, a total of 64 patients were treated with either percutaneous cryoablation $(n=31)$ or RF ablation $(n=33)$ for unresectable hepatic malignancies, and the outcomes were compared between the two modalities. ${ }^{94}$ Complication rates were $29 \%$ in the cryoablation group and $8 \%$ in RF ablation group. Although initial treatment success was comparable between the two groups, the local recurrence rate was higher in patients treated with cryoablation than those treated with RF ablation (53 vs. 18\%). Another prospective study comparing intraoperative cryoablation and RF ablation also demonstrated a much higher complication rate for cryoablation (41 vs. $3 \%$ ). ${ }^{95}$

Major disadvantages of cryoablation include a variable ablation zone, cold-sink effect from adjacent vessels, and high complication risk. Local complications are hemorrhage, cold injury to adjacent organs, biliary injury, and hepatic parenchymal damage. ${ }^{96}$ Ice ball formation inside the liver may cause cracking or shearing of the liver parenchyma, resulting in major hemorrhage by extension of shearing injury to major vessels. Late hemorrhage and intrahepatic abscess can occur by biliary injury. Cryoablation is also associated with the cytokine-mediated systemic syndrome, which is known as "cryoshock" and includes fever, tachycardia, and tachypnea. Although cryoablation has some potential advantages, its utility in the treatment of liver malignancies is limited mainly due to the higher complication rates, higher local recurrence rates, and the lack of proven efficacy benefit compared with other thermal ablation methods. ${ }^{8,97}$

\section{Conclusion}

Although PEI is well established and is the most commonly used chemical ablation technique for small HCC, due to its higher local recurrence rates and lower disease-free survival, RF ablation should be considered the first-line treatment modality in the treatment of primary and secondary liver malignancies. However, conventional RF technology is significantly limited for large $\mathrm{HCC}(\geq 5 \mathrm{~cm})$ mainly by incomplete tumor necrosis. As the technology in RF devices continues to advance, the efficacy is clearly improved with complete ablation rates for larger tumors now reported in the 81 to $90 \%$ range. In addition, newer technologies are being advanced that give hope to expanding the types of lesions that may be treated while potentially reducing the complications. MW ablation has different underlying mechanisms for generating heat and is less affected by a heat sink from adjacent large vessels. Other thermal ablation techniques that also use heat include laser ablation and HIFU. For small HCC, both techniques provide good outcomes comparable to that of RF ablation. IRE is a nonthermal ablation method with lack of a heat-sink effect, thus enabling better tumor ablation with less risk of damage to the adjacent vessels, ducts, or critical organs. For this reason, interest in IRE continues to increase for tumors in the pancreas or liver where vital structures can easily be damaged by heat. Despite some potential 
advantages, the use of cryoablation for liver tumors is still limited by higher complication rates and the lack of proven efficacy benefit over other techniques.

\section{References}

1 Stigliano R, Marelli L, Yu D, Davies N, Patch D, Burroughs AK. Seeding following percutaneous diagnostic and therapeutic approaches for hepatocellular carcinoma. What is the risk and the outcome? Seeding risk for percutaneous approach of HCC. Cancer Treat Rev 2007;33(5):437-447

2 Clark TW, Soulen MC. Chemical ablation of hepatocellular carcinoma. J Vasc Interv Radiol 2002;13(9, Pt 2):S245-S252

3 Shiina S, Tagawa K, Niwa Y, et al. Percutaneous ethanol injection therapy for hepatocellular carcinoma: results in 146 patients. AJR Am J Roentgenol 1993;160(5):1023-1028

4 Lencioni R, Bartolozzi C, Caramella D, et al. Treatment of small hepatocellular carcinoma with percutaneous ethanol injection. Analysis of prognostic factors in 105 Western patients. Cancer 1995;76(10):1737-1746

5 Livraghi T, Giorgio A, Marin G, et al. Hepatocellular carcinoma and cirrhosis in 746 patients: long-term results of percutaneous ethanol injection. Radiology 1995;197(1):101-108

6 Da Ines D, Buc E, Petitcolin V, et al. Massive hepatic necrosis with gastric, splenic, and pancreatic infarctions after ethanol ablation for hepatocellular carcinoma. J Vasc Interv Radiol 2010;21(8): 1301-1305

7 Hasegawa S, Yamasaki N, Hiwaki T, et al. Factors that predict intrahepatic recurrence of hepatocellular carcinoma in 81 patients initially treated by percutaneous ethanol injection. Cancer 1999; 86(9):1682-1690

8 McWilliams JP, Yamamoto S, Raman SS, et al. Percutaneous ablation of hepatocellular carcinoma: current status. J Vasc Interv Radiol 2010;21(8, Suppl):S204-S213

9 Shiina S, Teratani T, Obi S, et al. A randomized controlled trial of radiofrequency ablation with ethanol injection for small hepatocellular carcinoma. Gastroenterology 2005;129(1):122-130

10 Lin SM, Lin CJ, Lin CC, Hsu CW, Chen YC. Radiofrequency ablation improves prognosis compared with ethanol injection for hepatocellular carcinoma $<$ or $=4 \mathrm{~cm}$. Gastroenterology 2004;127(6): 1714-1723

11 Lencioni RA, Allgaier HP, Cioni D, et al. Small hepatocellular carcinoma in cirrhosis: randomized comparison of radio-frequency thermal ablation versus percutaneous ethanol injection. Radiology 2003;228(1):235-240

12 Cho YK, Kim JK, Kim MY, Rhim H, Han JK. Systematic review of randomized trials for hepatocellular carcinoma treated with percutaneous ablation therapies. Hepatology 2009;49(2):453-459

13 Orlando A, Leandro G, Olivo M, Andriulli A, Cottone M. Radiofrequency thermal ablation vs. percutaneous ethanol injection for small hepatocellular carcinoma in cirrhosis: meta-analysis of randomized controlled trials. Am J Gastroenterol 2009;104(2): 514-524

14 Shiina S, Tagawa K, Unuma T, et al. Percutaneous ethanol injection therapy for hepatocellular carcinoma. A histopathologic study. Cancer 1991;68(7):1524-1530

15 Swabb EA, Wei J, Gullino PM. Diffusion and convection in normal and neoplastic tissues. Cancer Res 1974;34(10):2814-2822

16 Ohnishi K, Ohyama N, Ito S, Fujiwara K. Small hepatocellular carcinoma: treatment with US-guided intratumoral injection of acetic acid. Radiology 1994;193(3):747-752

17 Ohnishi K, Nomura F, Ito S, Fujiwara K. Prognosis of small hepatocellular carcinoma (less than $3 \mathrm{~cm}$ ) after percutaneous acetic acid injection: study of 91 cases. Hepatology 1996;23(5):994-1002

18 Ohnishi K, Yoshioka H, Ito S, Fujiwara K. Prospective randomized controlled trial comparing percutaneous acetic acid injection and percutaneous ethanol injection for small hepatocellular carcinoma. Hepatology 1998;27(1):67-72

19 Tamai T, Seki T, Imamura M, et al. Percutaneous injection of a lowconcentration alkaline solution targeting hepatocellular carcinoma. Oncol Rep 2000;7(4):719-723

20 Farnam JL, Smith BC, Johnson BR, et al. Thermochemical ablation in an ex-vivo porcine liver model using acetic acid and sodium hydroxide: proof of concept. J Vasc Interv Radiol 2010;21(10): 1573-1578

21 Rubinsky B, Onik G, Mikus P. Irreversible electroporation: a new ablation modality-clinical implications. Technol Cancer Res Treat 2007;6(1):37-48

22 Davalos RV, Mir IL, Rubinsky B. Tissue ablation with irreversible electroporation. Ann Biomed Eng 2005;33(2):223-231

23 Miller L, Leor J, Rubinsky B. Cancer cells ablation with irreversible electroporation. Technol Cancer Res Treat 2005;4(6):699-705

24 Edd JF, Horowitz L, Davalos RV, Mir LM, Rubinsky B. In vivo results of a new focal tissue ablation technique: irreversible electroporation. IEEE Trans Biomed Eng 2006;53(7):1409-1415

25 Melikov KC, Frolov VA, Shcherbakov A, Samsonov AV, Chizmadzhev YA, Chernomordik LV. Voltage-induced nonconductive prepores and metastable single pores in unmodified planar lipid bilayer. Biophys J 2001;80(4):1829-1836

26 Lee EW, Chen C, Prieto VE, Dry SM, Loh CT, Kee ST. Advanced hepatic ablation technique for creating complete cell death: irreversible electroporation. Radiology 2010;255(2):426-433

27 Thomson KR, Cheung W, Ellis SJ, et al. Investigation of the safety of irreversible electroporation in humans. J Vasc Interv Radiol 2011; 22(5):611-621

28 Narayanan G, Hosein PJ, Arora G, et al. Percutaneous irreversible electroporation for downstaging and control of unresectable pancreatic adenocarcinoma. J Vasc Interv Radiol 2012;23(12): 1613-1621

29 Kingham TP, Karkar AM, D'Angelica MI, et al. Ablation of perivascular hepatic malignant tumors with irreversible electroporation. J Am Coll Surg 2012;215(3):379-387

30 Silk MT, Wimmer T, Lee KS, et al. Percutaneous ablation of peribiliary tumors with irreversible electroporation. J Vasc Interv Radiol 2014;25(1):112-118

31 Cannon R, Ellis S, Hayes D, Narayanan G, Martin RC II. Safety and early efficacy of irreversible electroporation for hepatic tumors in proximity to vital structures. J Surg Oncol 2013;107(5):544-549

$32 \mathrm{Ng} \mathrm{KK}$, Poon RT, Chan SC, et al. High-intensity focused ultrasound for hepatocellular carcinoma: a single-center experience. Ann Surg 2011;253(5):981-987

33 Wu F, Wang ZB, Chen WZ, et al. Extracorporeal high intensity focused ultrasound ablation in the treatment of 1038 patients with solid carcinomas in China: an overview. Ultrason Sonochem 2004; 11(3-4):149-154

34 Lynn JG, Zwemer RL, Chick AJ, Miller AE. A new method for the generation and use of focused ultrasound in experimental biology. J Gen Physiol 1942;26(2):179-193

35 Shen HP, Gong JP, Zuo GQ. Role of high-intensity focused ultrasound in treatment of hepatocellular carcinoma. Am Surg 2011; 77(11):1496-1501

36 Mearini L, Porena M. Transrectal high-intensity focused ultrasound for the treatment of prostate cancer: past, present, and future. Indian J Urol 2010;26(1):4-11

37 Kennedy JE, Ter Haar GR, Cranston D. High intensity focused ultrasound: surgery of the future? Br J Radiol 2003;76(909): 590-599

38 Zhu J, Zhu H, Mei Z, et al. High-intensity focused ultrasound ablation for treatment of hepatocellular carcinoma and hypersplenism: preliminary study. J Ultrasound Med 2013;32(10): 1855-1862

39 Hesley GK, Gorny KR, Woodrum DA. MR-guided focused ultrasound for the treatment of uterine fibroids. Cardiovasc Intervent Radiol 2013;36(1):5-13 
40 Mearini L. High intensity focused ultrasound, liver disease and bridging therapy. World J Gastroenterol 2013;19(43): 7494-7499

$41 \mathrm{Xu} \mathrm{G}$, Luo G, He L, et al. Follow-up of high-intensity focused ultrasound treatment for patients with hepatocellular carcinoma. Ultrasound Med Biol 2011;37(12):1993-1999

42 Zhang L, Zhu H, Jin C, et al. High-intensity focused ultrasound (HIFU): effective and safe therapy for hepatocellular carcinoma adjacent to major hepatic veins. Eur Radiol 2009;19(2):437-445

43 Cheung TT, Fan ST, Chu FS, et al. Survival analysis of high-intensity focused ultrasound ablation in patients with small hepatocellular carcinoma. HPB (Oxford) 2013;15(8):567-573

44 Pacella CM, Bizzarri G, Cecconi P, et al. Hepatocellular carcinoma: long-term results of combined treatment with laser thermal ablation and transcatheter arterial chemoembolization. Radiology 2001;219(3):669-678

45 Wu F, Wang ZB, Chen WZ, et al. Advanced hepatocellular carcinoma: treatment with high-intensity focused ultrasound ablation combined with transcatheter arterial embolization. Radiology 2005;235(2):659-667

46 Jin C, Zhu H, Wang Z, et al. High-intensity focused ultrasound combined with transarterial chemoembolization for unresectable hepatocellular carcinoma: long-term follow-up and clinical analysis. Eur J Radiol 2011;80(3):662-669

47 Vaezy S, Martin R, Keilman G, et al. Control of splenic bleeding by using high intensity ultrasound. J Trauma 1999;47(3):521-525

48 Noble ML, Vaezy S, Keshavarzi A, et al. Spleen hemostasis using high-intensity ultrasound: survival and healing. J Trauma 2002; 53(6):1115-1120

49 Shi B, Zhu H, Liu YJ, et al. Experimental studies and clinical experiences on treatment of secondary hypersplenism with extracorporeal high-intensity focused ultrasound. Ultrasound Med Biol 2012;38(11):1911-1917

50 Pacella CM, Francica G, Di Costanzo GG. Laser ablation for small hepatocellular carcinoma. Radiol Res Pract 2011;2011:595627

51 Masters A, Bown SG. Interstitial laser hyperthermia in tumour therapy. Ann Chir Gynaecol 1990;79(4):244-251

52 Thomsen S. Pathologic analysis of photothermal and photomechanical effects of laser-tissue interactions. Photochem Photobiol 1991;53(6):825-835

53 Jacques SL. Laser-tissue interactions. Photochemical, photothermal, and photomechanical. Surg Clin North Am 1992;72(3): 531-558

54 Di Costanzo GG, D’Adamo G, Tortora R, et al. A novel needle guide system to perform percutaneous laser ablation of liver tumors using the multifiber technique. Acta Radiol 2013;54(8):876-881

55 Bown SG. Phototherapy in tumors. World J Surg 1983;7(6): 700-709

56 Wyman DR, Whelan WM, Wilson BC. Interstitial laser photocoagulation: Nd:YAG 1064. nm optical fiber source compared to point heat source. Lasers Surg Med 1992;12(6):659-664

57 Germer CT, Roggan A, Ritz JP, et al. Optical properties of native and coagulated human liver tissue and liver metastases in the near infrared range. Lasers Surg Med 1998;23(4):194-203

58 Ritz JP, Roggan A, Germer CT, Isbert C, Müller G, Buhr HJ. Continuous changes in the optical properties of liver tissue during laser-induced interstitial thermotherapy. Lasers Surg Med 2001; 28(4):307-312

59 Tranberg KG. Percutaneous ablation of liver tumours. Best Pract Res Clin Gastroenterol 2004;18(1):125-145

60 Pacella CM, Bizzarri G, Francica G, et al. Percutaneous laser ablation in the treatment of hepatocellular carcinoma with small tumors: analysis of factors affecting the achievement of tumor necrosis. J Vasc Interv Radiol 2005;16(11):1447-1457

61 Arienti V, Pretolani S, Pacella CM, et al. Complications of laser ablation for hepatocellular carcinoma: a multicenter study. Radiology 2008;246(3):947-955
62 Puls R, Langner S, Rosenberg C, et al. Laser ablation of liver metastases from colorectal cancer with MR thermometry: 5year survival. J Vasc Interv Radiol 2009;20(2):225-234

63 Orlacchio A, Bolacchi F, Chegai F, et al. Comparative evaluation of percutaneous laser and radiofrequency ablation in patients with HCC smaller than $4 \mathrm{~cm}$. Radiol Med (Torino) 2013

64 Zou X, Liu Q Zhou X, et al. Ultrasound-guided percutaneous laser and ethanol ablation of rabbit VX2 liver tumors. Acta Radiol 2013; 54(2):181-187

65 Chen MS, Li JQ Zheng Y, et al. A prospective randomized trial comparing percutaneous local ablative therapy and partial hepatectomy for small hepatocellular carcinoma. Ann Surg 2006; 243(3):321-328

66 McGahan JP, Browning PD, Brock JM, Tesluk H. Hepatic ablation using radiofrequency electrocautery. Invest Radiol 1990;25(3): 267-270

67 Buscarini E, Savoia A, Brambilla G, et al. Radiofrequency thermal ablation of liver tumors. Eur Radiol 2005;15(5):884-894

68 Brace CL. Radiofrequency and microwave ablation of the liver, lung, kidney, and bone: what are the differences? Curr Probl Diagn Radiol 2009;38(3):135-143

69 Nicoli N, Casaril A, Marchiori L, et al. Intraoperative and percutaneous radiofrequency thermal ablation in the treatment of hepatocellular carcinoma. Chir Ital 2000;52(1):29-40

70 Grasso A, Watkinson AF, Tibballs JM, Burroughs AK. Radiofrequency ablation in the treatment of hepatocellular carcinoma-a clinical viewpoint. J Hepatol 2000;33(4):667-672

71 Dong B, Liang P, Yu X, et al. Percutaneous sonographically guided microwave coagulation therapy for hepatocellular carcinoma: results in 234 patients. AJR Am J Roentgenol 2003;180(6): 1547-1555

72 Lu MD, Xu HX, Xie XY, et al. Percutaneous microwave and radiofrequency ablation for hepatocellular carcinoma: a restrospective comparative study. J Gastroenterol 2005;40(11):1054-1060

73 Shibata T, limuro Y, Yamamoto Y, et al. Small hepatocellular carcinoma: comparison of radio-frequency ablation and percutaneous microwave coagulation therapy. Radiology 2002;223(2): 331-337

74 Poggi G, Montagna B, DI Cesare P, et al. Microwave ablation of hepatocellular carcinoma using a new percutaneous device: preliminary results. Anticancer Res 2013;33(3):1221-1227

75 Shibata T, Niinobu T, Ogata N, Takami M. Microwave coagulation therapy for multiple hepatic metastases from colorectal carcinoma. Cancer 2000;89(2):276-284

76 Tanaka K, Shimada H, Nagano Y, Endo I, Sekido H, Togo S. Outcome after hepatic resection versus combined resection and microwave ablation for multiple bilobar colorectal metastases to the liver. Surgery 2006;139(2):263-273

77 Cammà C, Di Marco V, Orlando A, et al; Unità Interdipartimentale Neoplasie Epatiche (U.I.N.E) Group. Treatment of hepatocellular carcinoma in compensated cirrhosis with radio-frequency thermal ablation (RFTA): a prospective study. J Hepatol 2005;42(4): 535-540

78 Lencioni R, Cioni D, Crocetti L, et al. Early-stage hepatocellular carcinoma in patients with cirrhosis: long-term results of percutaneous image-guided radiofrequency ablation. Radiology 2005; 234(3):961-967

79 Tateishi R, Shiina S, Teratani T, et al. Percutaneous radiofrequency ablation for hepatocellular carcinoma. An analysis of 1000 cases. Cancer 2005;103(6):1201-1209

80 Guglielmi A, Ruzzenente A, Sandri M, et al. Radio frequency ablation for hepatocellular carcinoma in cirrhotic patients: prognostic factors for survival. J Gastrointest Surg 2007;11(2):143-149

81 Guglielmi A, Ruzzenente A, Battocchia A, Tonon A, Fracastoro G, Cordiano $C$. Radiofrequency ablation of hepatocellular carcinoma in cirrhotic patients. Hepatogastroenterology 2003;50(50): 480-484 
82 Seror O, N'Kontchou G, Ibraheem M, et al. Large ( $>$ or $=5.0-\mathrm{cm}$ ) HCCs: multipolar RF ablation with three internally cooled bipolar electrodes-initial experience in 26 patients. Radiology 2008; 248(1):288-296

83 Kuang M, Lu MD, Xie XY, et al. Liver cancer: increased microwave delivery to ablation zone with cooled-shaft antenna-experimental and clinical studies. Radiology 2007;242(3):914-924

84 Tiong L, Maddern GJ. Systematic review and meta-analysis of survival and disease recurrence after radiofrequency ablation for hepatocellular carcinoma. Br J Surg 2011;98(9):1210-1224

85 Lin SM, Lin CJ, Lin CC, Hsu CW, Chen YC. Randomised controlled trial comparing percutaneous radiofrequency thermal ablation, percutaneous ethanol injection, and percutaneous acetic acid injection to treat hepatocellular carcinoma of $3 \mathrm{~cm}$ or less. Gut 2005;54(8):1151-1156

86 O'Rourke AP, Haemmerich D, Prakash P, Converse MC, Mahvi DM, Webster JG. Current status of liver tumor ablation devices. Expert Rev Med Devices 2007;4(4):523-537

87 Erinjeri JP, Clark TW. Cryoablation: mechanism of action and devices. J Vasc Interv Radiol 2010;21(8, Suppl):S187-S191

88 Bryant G. DSC measurement of cell suspensions during successive freezing runs: implications for the mechanisms of intracellular ice formation. Cryobiology 1995;32(2):114-128

89 Baust JG, Gage AA. The molecular basis of cryosurgery. BJU Int 2005;95(9):1187-1191
90 Finelli A, Rewcastle JC, Jewett MA. Cryotherapy and radiofrequency ablation: pathophysiologic basis and laboratory studies. Curr Opin Urol 2003;13(3):187-191

91 Weber SM, Lee FT Jr, Chinn DO, Warner T, Chosy SG, Mahvi DM. Perivascular and intralesional tissue necrosis after hepatic cryoablation: results in a porcine model. Surgery 1997;122(4): 742-747

92 Sheen AJ, Poston GJ, Sherlock DJ. Cryotherapeutic ablation of liver tumours. Br J Surg 2002;89(11):1396-1401

$93 \mathrm{Xu} \mathrm{KC}$, Niu LZ, Zhou Q et al. Sequential use of transarterial chemoembolization and percutaneous cryosurgery for hepatocellular carcinoma. World J Gastroenterol 2009;15(29):3664-3669

94 Adam R, Hagopian EJ, Linhares M, et al. A comparison of percutaneous cryosurgery and percutaneous radiofrequency for unresectable hepatic malignancies. Arch Surg 2002;137(12):1332-1339, discussion 1340

95 Pearson AS, Izzo F, Fleming RY, et al. Intraoperative radiofrequency ablation or cryoablation for hepatic maligancies. Am J Surg 1999; 178(6):592-599

96 Seifert JK, Morris DL. World survey on the complications of hepatic and prostate cryotherapy. World J Surg 1999;23(2):109-113, discussion 113-114

97 Sheen AJ, Siriwardena AK. The end of cryotherapy for the treatment of nonresectable hepatic tumors? Ann Surg Oncol 2005; 12(3):202-204 